\title{
ANALISIS FAKTOR YANG MEMPENGARUHI MINAT MAHASISWA BERWIRAUSAHA DENGAN METODE ELECTRE II
}

\author{
Laila Safitri ${ }^{1}$, Poningsih ${ }^{2}$, Jalaluddin ${ }^{3}$ \\ ${ }^{1}$ Mahasiswa Program Studi Sistem Informasi, STIKOM Tunas Bangsa Pematangsiantar \\ ${ }^{2,3}$ Dosen STIKOM Tunas Bangsa Pematangsiantar \\ Email : ${ }^{1}$ lailasafitri129@gmail.com, ${ }^{2}$ poningsih@amiktunasbangsa.ac.id, ${ }^{3}$ jalaluddin@ @amiktunasbangsa.ac.id
}

\begin{abstract}
Abstrak
Penelitian ini bertujuan untuk mengetahui faktor yang paling mendasar dalam mempengaruhi minat mahasiswa berwirausaha di PematangSiantar. Metode yang digunakan dalam pengambilan keputusan adalah metode ELECTRE II. Yang akan di implementasikan ke dalam aplikasi $\mathrm{Vb}$ Net 2010. Berdasarkan hasil penelitian diperoleh Modal (A3) sebagai peringkat 1, penelitian ini memberikan masukan dan kemudahan dalam mengetahui faktor mendasar yang mempengaruhi minat mahasiswa dalam berwirausaha.
\end{abstract}

Kata Kunci : Mahasiswa, Minat, Wirausaha, SPK, Electre II.

\begin{abstract}
This study aims to determine the most fundamental factors in influencing student interest in entrepreneurship at Pematangsianta. The method used in decision making is the ELECTRE II method. Which will be implemented into vb net 2010. Based on the research results obtained by Capital (A3) as rank 1, It is hoped that this research will provide input and convenience to the education parties in knowing what fundamental factors influence student interest in entrepreneurship.
\end{abstract}

Keywords: Students, Interests, Entrepreneurship, SPK, Electre II.

\section{PENDAHULUAN}

Pembangunan sumber daya manusia perlu dilaksanakan secara menyeluruh, terarah, dan terpandu di berbagai bidang, terutama yang mencakup bidang pendidikan, latihan, serta penyediaan lapangan kerja. Pengembangan kemampuan intelektual, keterampilan dan kreativitas sangat diperlukan oleh setiap pelaku wirausaha, sehingga mereka mampu mandiri dan selalu berupaya meningkatkan etos kerja yang selajutnya mereka dapat memperoleh kesempatan kerja atau membuka usaha sendiri (berwirausaha)[1].

Wirausaha adalah seorang pembuat keputusan yang membantu terbentuknya sistem ekonomi perusahaan yang bebas. Sebagian besar pendorong perubahan, inovasi, dan kemajuan dalam dunia perekonomian datang dari para wirausaha, orang-orang yang memiliki kemampuan untuk mengambil resiko dan mempercepat pertumbuhan ekonomi. Minat tersebut tidak dibawa sejak lahir tetapi tumbuh dan berkembang sesuai dengan faktor-faktor yang mempengaruhinya. Faktor-faktor tersebut antara lain faktor dari dalam (internal), faktor luar (external), dan faktor emosi, jadi faktor-faktor itulah yang nantinya akan memperkuat atau memperlemah minat[2].

Dalam penelitian, data yang digunakan akan diolah dari hasil kuesioner yang diberikan kepada mahasiswa STIKOM Tunas Bangsa angkatan 2015. Kriteria yang digunakan dalam kuesioner yaitu: Tantangan Pribadi Inovasi Modal Kebebasan. Kriteria terdiri dari pertanyaan yang diajukan ke mahasiswa yang diberikan. Kuesioner yang telah dilakukan selanjutnya mencari perengkingan dari kriteria yang digunakan. Data yang digunakan menggunakan jenis statistik inferensial. Statistik inferensial adalah statistik yang berkaitan dengan analisis data (sampel), kemudian diambil kesimpulan yang digeneralisasikan kepada seluruh populasi dan digunakan untuk menarik inferensi dari sampel ke populasi.

\section{TEORITIS}

\subsection{Sistem Pendukung Keputusan}

Sistem Pendukung Keputusan (SPK) merupakan suatu pendekatan atau metodelogi untuk mendukung keputusan[3]. SPK menggunakan CBIS (Computer Based Information System) yang fleksibel, interaktif dan dapat di atasi, yang dikembangkan untuk mendukung solusi untuk masalah manajemen spesifik yang tidak terstruktur. SPK menggunakan data, memberikan antarmuka pengguna yang mudah dan dapat menggabungkan pemikiran pengambil keputusan[4][5].

\subsection{Algoritma Elimination Et Choix Traduisant La Realite II (ELECTRE II)}

Metode ELECTRE II sebagai salah satu metode MADM secara luas diakui mempunyai performa yang baik untuk menganalisis kebijakan yang melibatkan kriteria kualitatif dan kuantitatif. Metode ELECTRE II telah berkembang melalui sejumlah versi (I, II, III, IV, 1S). Semua versi didasarkan pada konsep dasar yang sama namun secara operasional berbeda. Metode ELECTRE II didesain untuk pemilihan sedangkan ELECTRE II digunakan untuk perankingan. Kedua versi ini menggunakan tipe kriteria yang sederhana, dalam arti nilai threshold-nya sama untuk 
semua kriteria sedangkan versi yang lain menggunakan pseudo criteria yang nilai threshold-nya tidak sama untuk semua kriteria [6].

Tahap-tahap metode Electre II dapat dilihat seperti dibawah ini: [6].

1. Tujuan normalisasi adalah untuk mendapatkan nilai berdimensi dengan kriteria yang berbeda agar keduanya dapat dibandingkan satu sama lain. Dalam prosedur ini, setiap atribut diubah menjadi nilai yang comparable. Setiap normalisasi dari nilai rij dapat dilakukan dengan rumus :

$r_{i j}=\frac{X_{i j}}{\sum_{i=1}^{m} X_{i j}^{2}}$

2. Pembobotan pada matrik yang telah dinormalisasi. Setelah di normalisasi, setiap kolom dari matrik R dikalikan dengan bobot-bobot (wj) yang ditentukan oleh pembuat keputusan. Sehingga, weighted normalized matrix adalah $\mathrm{V}=\mathrm{RW}$ yang ditulis dalam rumus ini :

$$
R_{w}=\left[\begin{array}{cccc}
W_{1} r_{11} & W_{1} r_{12} & \ldots & W_{n} r_{1 n} \\
W_{2} r_{21} & W_{2} w_{12} & \ldots & w_{n} r_{1 n} \\
\ldots & \ldots & \ldots & \ldots \\
W_{m} r_{m 1} & W_{2} v_{m 2} & \ldots & W_{n} r_{m n}
\end{array}\right]
$$

3. Menentukan concordance dan discordance set. Untuk mencari nilai concordance adalah:

$C_{k l}=\{\mathrm{j}$, ykj $\geq$ yij $\}$, untuk j $=1,2,3, \ldots, \mathrm{n}$;

sebaliknya untuk mencari nilai discordance adalah :

$D_{k l}=\{\mathrm{j}$, ykj $<$ yij $\}$, untuk $\mathrm{j}=1,2,3, \ldots, \mathrm{n}$;

4. Hitung matriks concordance dan discordance.

a. Concordance, Untuk menentukan nilai dari elemen-elemen pada matriks concordance adalah dengan menjumlahkan bobot-bobot yang termasuk dalam subset concordance, secara matematisnya adalah pada Rumus :

$$
C_{k l}=\sum j c w W j
$$

b. Discordance, Untuk menentukan nilai dari elemenelemen pada matriks discordance adalah dengan membagi maksimum selisih nilai kriteria yang termasuk dalam subsetdiscordance dengan maksimum selisih nilai seluruh kriteria yang ada, secara matematisnya adalah sebagai berikut:

$D_{k l}=\frac{\{\max (v m n-v m n-1 n)\} ; m, n \in D k l}{\{\max (v m n-v m n-1 n)\} ; m, n \quad=1,2,3}$

5. Menentukan matrik dominan concordance dan discordance.

a. Concordance, Matrik dominan concordance dapat dibangun dengan bantuan nilai threshold, yaitu dengan membandingkan setiap nilai elemen matriks concordance dengan nilai threshold C'.

$C_{k l} \geq C^{\prime}$

$C^{\prime}=\frac{\sum n k=1 \sum n i=1}{C_{k l m} *(\mathrm{~m}-1)}$

Dengan nilai treshold $\mathrm{c}$ adalah

Dan nilai setiap elemen matriks f sebagai matriks dominan concordance ditentukan sbb :

$f_{k l}=1$, jika $c_{k l} \geq c^{\prime}$ dan $f_{k l}=0$, jika $c_{k l}<c^{\prime}$

b. Discordance, Untuk membangun matriks dominan discordance juga menggunakan bantuan nilai threshold d' yaitu :

$D^{\prime}=\frac{\sum \mathrm{n} \mathrm{k}=1 \sum \mathrm{n} \mathrm{i}=1 \mathrm{Dkl}}{\mathrm{m} * \quad(\mathrm{~m}-1)}$

Dan nilai setiap elemen untuk matriks g sebagai matriks dominan discordance ditentukan sebagai berikut:

$G_{k l}=0$, jika $D_{k l} \geq D^{\prime}$ dan $G_{k l}=1$, jika $D_{k l}<D^{\prime}$

6. Menentukan concordance murni dan discordance murni.

a. Concordance murni, dicari dengan mengurangkan nilai perbaris dengan kolom dari matriks concordance yang mana masing-masing baris dan kolom dijumlahkan. Rumus mencarinya sebagai berikut:

$J_{j}=\sum n k=1 c(j, k)-\sum n k=1 C(k, j),(j \neq k)$

b. Discordance murni, dicari dengan mengurangkan nilai perbaris dengan kolom dari matriks discordance yang mana masing-masing baris dan kolom dijumlahkan. Rumus mencarinya sebagai berikut:

$D_{j}=\sum n k=1 d(j, k)-\sum n k=1 d(k, j),(j \neq k)$

\section{ANALISA DAN PEMBAHASAN}

\subsection{Proses Perhitungan}

Tabel 1. Data Alternatif

\begin{tabular}{lcccccccccc}
\hline \multirow{2}{*}{ Alternatif } & \multicolumn{10}{c}{ Kriteria } \\
\cline { 2 - 11 } & C1 & C2 & C3 & C4 & C5 & C6 & C7 & C8 & C9 & C10 \\
\hline Tantangan Pribadi & 2,67 & 3,67 & 3,67 & 3,67 & 3,67 & 4 & 3,67 & 3,33 & 3,67 & 3,67 \\
Inovasi & 4 & 4,33 & 3,00 & 3,33 & 4 & 3,33 & 4 & 3,33 & 3,33 & 3,67 \\
\hline
\end{tabular}




\begin{tabular}{lcccccccccc}
\hline Modal & 3 & 5 & 5 & 4,50 & 4 & 3,50 & 4,50 & 4 & 4,50 & 4 \\
Kebebasan & 3 & 4,50 & 4,50 & 4 & 3,50 & 4 & 4,50 & 4,50 & 4,50 & 4 \\
\hline \multicolumn{10}{c}{ Tabel 2. Data Lanjutan Alternatif } \\
\hline \multicolumn{1}{c}{ Alternatif } & \multicolumn{10}{c}{ Kriteria } \\
& $\mathbf{c}$ & $\mathbf{C 1 2}$ & $\mathbf{C 1 3}$ & $\mathbf{C 1 4}$ & $\mathbf{C 1 5}$ & $\mathbf{C 1 6}$ & $\mathbf{C 1 7}$ & $\mathbf{C 1 8}$ & $\mathbf{C 1 9}$ & $\mathbf{C 2 0}$ \\
\hline Tantangan Pribadi & 4,33 & 3,33 & 4 & 4,33 & 3,67 & 4,67 & 3,67 & 3,67 & 3,67 & 3,33 \\
Inovasi & 4 & 3,67 & 4 & 4,33 & 4 & 4,33 & 3,67 & 3,67 & 3,33 & 3 \\
Modal & 5 & 4,50 & 4 & 4,50 & 5 & 4 & 4 & 4 & 4,50 & 2,50 \\
Kebebasan & 4,50 & 4 & 4,50 & 5 & 5 & 4,50 & 4 & 4 & 5 & 3,50 \\
\hline
\end{tabular}

1. Normalisasi Keputusan

Dalam prosedur ini, setiap atribut diubah menjadi nilai yang compareable. Setiap normalisasi dapat dilakukan dengan persamaan (1)

$$
\begin{aligned}
& X_{1}=\sqrt{(2,67)^{2}+(4)^{2}+(3)^{2}+(3)^{2}}=36,67 \\
& r_{13}=\frac{3,67}{57,92}=0,0633 \\
& r_{23}=\frac{3,00}{57,92}=0,0518 \\
& r_{33}=\frac{5}{57,92}=0,0863 \\
& r_{43}=\frac{4.50}{57,92}=0,0777
\end{aligned}
$$

Tabel 3. Normalisasi Nilai Matriks

\begin{tabular}{cccccccccc}
\hline $\mathbf{C}_{\mathbf{1}}$ & $\mathbf{C}_{\mathbf{2}}$ & $\mathbf{C}_{\mathbf{3}}$ & $\mathbf{C}_{\mathbf{4}}$ & $\mathbf{C}_{\mathbf{5}}$ & $\mathbf{C}_{\mathbf{6}}$ & $\mathbf{C}_{\mathbf{7}}$ & $\mathbf{C}_{\mathbf{8}}$ & $\mathbf{C}_{\mathbf{9}}$ & $\mathbf{C}_{\mathbf{1 0}}$ \\
\hline 0,0727 & 0,0542 & 0,0633 & 0,0719 & 0,0765 & 0,0922 & 0,0609 & 0,0658 & 0,0663 & 0,0747 \\
0,1091 & 0,0640 & 0,0518 & 0,0653 & 0,0835 & 0,0769 & 0,0665 & 0,0658 & 0,0603 & 0,0747 \\
0,0818 & 0,0739 & 0,0863 & 0,0882 & 0,0835 & 0,0807 & 0,0748 & 0,0789 & 0,0814 & 0,0814 \\
0,0818 & 0,0665 & 0,0777 & 0,0784 & 0,0730 & 0,0922 & 0,0748 & 0,0888 & 0,0814 & 0,0814 \\
\hline
\end{tabular}

\begin{tabular}{ccccccccccc}
\hline \multicolumn{10}{c}{ Tabel 4. Lanjutan Normalisasi Nilai Matriks } \\
\hline $\mathbf{C}_{11}$ & $\mathbf{C}_{\mathbf{1 2}}$ & $\mathbf{C}_{\mathbf{1 3}}$ & $\mathbf{C}_{\mathbf{1 4}}$ & $\mathbf{C}_{\mathbf{1 5}}$ & $\mathbf{C}_{\mathbf{1 6}}$ & $\mathbf{C}_{\mathbf{1 7}}$ & $\mathbf{C}_{\mathbf{1 8}}$ & $\mathbf{C}_{\mathbf{1 9}}$ & $\mathbf{C}_{\mathbf{2 0}}$ \\
\hline 0,0661 & 0,0629 & 0,0711 & 0,0634 & 0,0526 & 0,0782 & 0,0747 & 0,0747 & 0,0611 & 0,1081 \\
0,0610 & 0,0691 & 0,0711 & 0,0634 & 0,0574 & 0,0726 & 0,0747 & 0,0747 & 0,0555 & 0,0973 \\
0,0762 & 0,0849 & 0,0711 & 0,0658 & 0,0718 & 0,0670 & 0,0814 & 0,0814 & 0,0750 & 0,0811 \\
0,0686 & 0,0754 & 0,0800 & 0,0731 & 0,0718 & 0,0754 & 0,0814 & 0,0814 & 0,0833 & 0,1135 \\
\hline
\end{tabular}

2. Pembobotan pada matrik

Pembobotan pada matriks yang telah dinormalisasi Matriks V merupakan hasil perkalian R dengan W(bobot), dimana $\mathrm{w}$ (bobot) dapat dilihat pada tabel 5 berikut.

Tabel 5. Matriks Setelah Dinormalisasikan $\left(\mathrm{R}^{*} \mathrm{~W}\right)$

\begin{tabular}{cccccccccc}
\hline $\mathbf{C}_{\mathbf{1}}$ & $\mathbf{C}_{\mathbf{2}}$ & $\mathbf{C}_{\mathbf{3}}$ & $\mathbf{C}_{\mathbf{4}}$ & $\mathbf{C}_{\mathbf{5}}$ & $\mathbf{C}_{\mathbf{6}}$ & $\mathbf{C}_{\mathbf{7}}$ & $\mathbf{C}_{\mathbf{8}}$ & $\mathbf{C}_{\mathbf{9}}$ & $\mathbf{C}_{\mathbf{1 0}}$ \\
\hline 0,0069 & 0,0049 & 0,0054 & 0,0058 & 0,0058 & 0,0066 & 0,0041 & 0,0041 & 0,0038 & 0,0039 \\
0,0104 & 0,0058 & 0,0044 & 0,0053 & 0,0064 & 0,0055 & 0,0044 & 0,0041 & 0,0034 & 0,0039 \\
0,0078 & 0,0067 & 0,0074 & 0,0071 & 0,0064 & 0,0058 & 0,0050 & 0,0049 & 0,0047 & 0,0043 \\
0,0078 & 0,0060 & 0,0067 & 0,0063 & 0,0056 & 0,0066 & 0,0050 & 0,0055 & 0,0047 & 0,0043 \\
\hline \multicolumn{8}{c}{ Tabel 6. Matriks Setelah Dinormalisasikan $\left(\mathrm{R}^{*} \mathrm{~W}\right)$} & & \\
\hline $\mathbf{C}_{\mathbf{1 1}}$ & $\mathbf{C}_{\mathbf{1 2}}$ & $\mathbf{C}_{\mathbf{1 3}}$ & $\mathbf{C}_{\mathbf{1 4}}$ & $\mathbf{C}_{\mathbf{1 5}}$ & $\mathbf{C}_{\mathbf{1 6}}$ & $\mathbf{C}_{\mathbf{1 7}}$ & $\mathbf{C}_{\mathbf{1 8}}$ & $\mathbf{C}_{\mathbf{1 9}}$ & $\mathbf{C}_{\mathbf{2 0}}$ \\
\hline 0,0031 & 0,0027 & 0,0027 & 0,0021 & 0,0015 & 0,0019 & 0,0014 & 0,0011 & 0,0006 & 0,0005 \\
0,0029 & 0,0030 & 0,0027 & 0,0021 & 0,0016 & 0,0017 & 0,0014 & 0,0011 & 0,0005 & 0,0005 \\
0,0036 & 0,0036 & 0,0027 & 0,0022 & 0,0021 & 0,0016 & 0,0016 & 0,0012 & 0,0007 & 0,0004 \\
0,0033 & 0,0032 & 0,0030 & 0,0024 & 0,0021 & 0,0018 & 0,0016 & 0,0012 & 0,0008 & 0,0005 \\
\hline
\end{tabular}

Menentukan himpunan concordance dan discordance index. Himpunan concordance, sebagai berikut: C12 =

$V 11 \geq V 21=0,0727 \geq 0,1091$ 
$V 12 \geq V 22=0,0542 \geq 0,0640$

$V 13 \geq V 23=0,0633 \geq 0,0863$

Menentukan himpunan discordance, sebagai berikut :

$D 12=$

$V 21 \geq V 11=0,1091 \geq 0,0727$

$V 22 \geq V 12=0,0640 \geq 0,0542$

$V 23 \geq V 13=0,0863 \geq 0,0633$

$V 24 \geq V 14=0,0653 \geq 0,0719$

Dan seterusnya hingga $C 2019$ Sehingga didapatkan himpunan concordance nya.

3. Hitung matriks concordance dan discordance.

a. Menghitung concordance, menggunakan persamaan (4), sebagai berikut :

$C 12=W 1+W 3+W 5+W 6+W 8$

$=0,0952+0,0857+0,0762+0,0714+0,0619$

$=0,3905$

dan seterusnya hingga C2019. Nilai dari komponen matriks disusun berdasarkan himpunan concordance dengan bobot $(\mathrm{W})$ dan dijumlahkan, sehingga menghasilkan matriks concordance sebagai berikut :

Tabel 6. Matriks Concordance

\begin{tabular}{cllll}
\hline Concordance & \multicolumn{1}{c}{$\mathbf{A 1}$} & \multicolumn{1}{c}{$\mathbf{A 2}$} & \multicolumn{1}{c}{$\mathbf{A 3}$} & \multicolumn{1}{c}{$\mathbf{A 4}$} \\
\hline A1 & - & 0,6000 & 0,1381 & 0,1762 \\
A2 & 0,6238 & - & 0,2381 & 0,2381 \\
A3 & 0,9000 & 0,9714 & - & 0,7571 \\
A4 & 0,9000 & 0,9238 & 0,5762 & - \\
\hline
\end{tabular}

b. Menghitung discordance., Untuk menghitung nilai dari elemen pada matriks discordance adalah dengan membagi maksimum selisih nilai kriteria yang termasuk dalam subset discordance dengan maksimum selisih nilai seluruh kriteria yang ada, secara matematisnya seperti pada Persamaan (5), sebagai berikut :

$$
D_{k l}=\frac{\operatorname{Max}\left\{\begin{array}{c}
(0,0069-0,0104) ;(0,0049-0,0058) ;(0,0041-0,0044) ; \\
(0,0038-0,0034) ;(0,0031-0,0029) ;(0,0027-0,0030) ; \\
(0,0015-0,0016)
\end{array}\right\}}{\operatorname{Max}\left\{\begin{array}{c}
(0,0069-0,0104) ;(0,0049-0,0058) ;(0,0054-0,0044) ; \\
(0,0058-0,0053) ;(0,0058-0,0064) ;(0,0066-0,0058) ; \\
(0,0041-0,0041) ;(0,0041-0,0041) ;(0,0038-0,0034) ; \\
(0,0027-0,0039) ;(0,0031-0,0029) ;(0,0027-0,0030) ; \\
(0,0019-0,0017) ;(0,0014-0,0014) ;(0,0011-0,0011) ; \\
(0,0006-0,0005)
\end{array}\right\}}
$$

Dan seterusnya sampai D1019, Sehingga diperoleh matriks discordance sebagai berikut:

Tabel 7. Matriks Discordance

\begin{tabular}{clllll}
\hline Discordance & A1 & A2 & A3 & A4 \\
\hline A1 & - & 1 & 1 & 1 \\
A2 & 1 & - & 1 & 0,8547 \\
A3 & 0,4174 & 0,8775 & - & 1 \\
A4 & 0 & 1 & 1 & - \\
\hline
\end{tabular}

4. Menentukan matriks dominan concordance dan discordance.

a. Matriks dominan concordance, Menghitung matriks dominan concordance Threshold didapat dari penjumlahan seluruh elemen matriks dibagi ukuran matriks yang terdapat pada persamaan. Sehingga matriks dominannya adalah :

Tabel 8. Matriks Dominan Concordance

\begin{tabular}{ccccc}
\hline Dominan Concordance & A1 & A2 & A3 & A4 \\
\hline A1 & - & 0 & 0 & 0 \\
A2 & 0 & - & 0 & 0 \\
A3 & 0 & 0 & - & 0 \\
A4 & 0 & 0 & 0 & - \\
\hline
\end{tabular}


b. Matriks dominan discordance, Menghitung matriks dominan Disconcordance Threshold didapat dari penjumlahan seluruh elemen matriks dibagi ukuran matriks yang terdapat pada persamaan(8). Sehingga matriks dominannya adalah:

Tabel 9. Matriks Dominan Discordance

\begin{tabular}{ccccc}
\hline Dominan Discordance & A1 & A2 & A3 & A4 \\
\hline A1 & - & 1 & 1 & 1 \\
A2 & 1 & - & 1 & 1 \\
A3 & 1 & 1 & - & 1 \\
A4 & 1 & 1 & 1 & - \\
\hline
\end{tabular}

5. Menghitung indeks concordance murni dan Discordance murni.

a. Concordance murni, Untuk mencari nilai concordance murni dapat dilihat pada persamaan (9).

$$
\begin{aligned}
& C 1=0,6238+0,9000+0,9000-(0,6000+0,1381+0,1762)=1,5095 \\
& C 2=0,6238+0,2381+0,2381-(0,6000+0,9714+0,9238)=-1,3952 \\
& C 3=0,9000+0,9714+0,7551-(0,1381+0,2381+0,5762)=1,6762 \\
& C 4=0,9000+0,9238+0,5762-(0,1762+0,2381+0,7571)=1,2286
\end{aligned}
$$

b. Discordance murni, Untuk mencari nilai discordance murni dapat dilihat pada persamaan (10).

$D 1=1+1+1-(1+0,4174+0)=2$

$D 2=1+1+0,8547-(1+0,8775+1)=-0,0228$

$D 3=0,4174+0,8775+1-(1+1+1)=-0,6703$

$D 4=0+1+1-(1+0,8547+1)=-0,8894$

Setelah kedua indeks telah dihitung, maka untuk mendapatkan alternatif terbaik adalah dengan mencari nilai rata rata dari kedua peringkat indeks concordance murni dan discordance murni. sehingga didapatkan peringkat peringkat sebagai berikut berdasarkan tabel 10 sebagai berikut.

Tabel 10. Perhitungan Alternatif Terbaik

\begin{tabular}{ccccccc}
\hline Faktor & Concordance & Rangking & Discordance & Rangking & $\begin{array}{c}\text { Average } \\
\text { Rank }\end{array}$ & $\begin{array}{c}\text { Final } \\
\text { Rank }\end{array}$ \\
\hline A1 & $-1,5095$ & 4 & 2 & 4 & 4 & 4 \\
A2 & $-1,3952$ & 3 & $-0,0228$ & 1 & 2 & 2 \\
A3 & 1,6762 & 1 & $-0,6703$ & 2 & 1 & 1 \\
A4 & 1,2286 & 2 & $-0,8894$ & 3 & 3 & 3 \\
\hline
\end{tabular}

\section{KESIMPULAN}

Berdasarkan pembahasan sebelumnya dapat disimpulkan bahwa hasil yang diperoleh perhitungan Electre II dan aplikasi Vb Net 2010 dapat digunakan untuk menyelesaikan faktor yang mempengaruhi minat mahasiswa berwirausaha. Hasil perhitungan manual sama dengan hasil program dengan menggunakan aplikasi yang telah dibuat adalah sama. Yaitu modal yang di dapatkan dari alternatif A3.

\section{REFERENCES}

[1] B. V. Christioko, H. Indriyawati, And N. Hidayati, Fuzzy Multi-Atribute Decision Making ( Fuzzy Madm ) Dengan Metode Saw Untuk Pemilihan Mahasiswa Berprestasi, J. Transform., Vol. 14, No. 2, Pp. 82-85, 2017.

[2] G. Mahmudi, A. Azis, I. Cholissodin, And M. T. Furqon, Sistem Pendukung Keputusan Untuk Rekomendasi Wirausaha Menggunakan Metode Ahp-Topsis (Studi Kasus Kab . Probolinggo), J. Pengemb. Teknol. Inf. Dan Ilmu Komput., Vol. 1, No. 11, Pp. 1204-1214, 2017.

[3] D. R. Sari, A. P. Windarto, D. Hartama, And S. Solikhun, Sistem Pendukung Keputusan Untuk Rekomendasi Kelulusan Sidang Skripsi Menggunakan Metode Ahp-Topsis, J. Teknol. Dan Sist. Komput., Vol. 6, No. 1, P. 1, 2018.

[4] T. Imandasari And A. P. Windarto, Sistem Pendukung Keputusan Dalam Merekomendasikan Unit Terbaik Di Pdam Tirta Lihou Menggunakan Metode Promethee, J. Teknol. Dan Sist. Komput., Vol. 5, No. 4, P. 159, 2017.

[5] H. Bartolomius And S. Palupi, Sistem Pendukung Keputusan Penerimaan Asisten Laboratorium Komputer Menggunakan Metode Simple Additive Weighting (Studi Kasus Pada Laboratorium Komputer Stmik Widya Cipta Dharma Samarinda), Pros. Semin. Ilm. Nas. Teknol. Komput. (Senatkom 2015), Vol. 1, No. Senatkom, Pp. 90-95, 2015.

[6] L. P. Purba, A. P. Windarto, And A. Wanto, Faktor Terbesar Rendahnya Minat Ber-Kb ( Keluarga Berencana ) Dengan Metode Electre II, Semin. Nas. Sains Teknol. Inf. Isbn, Pp. 369-374, 2018. 